\title{
HUBUNGAN ANTARA MOTIVASI BELAJAR DAN DISIPLIN DIRI DENGAN HASIL BELAJAR PRAKTIKUM INSTALASI MOTOR LISTRIK PROGRAM KEAHLIAN TEKNIK INSTALASI TENAGA LISTRIK STUDI KASUS SMK KAPIN JAKARTA
}

\author{
${ }^{1}$ Arifin Ramadhan, ${ }^{2}$ Suyitno, ${ }^{3}$ Irzan Zakir
}

${ }^{1,2,3}$ Pendidikan Vokasional Teknik Elektro, Fakultas Teknik, Universitas Negeri Jakarta

${ }^{1}$ E-mail : arifinramadhan22@gmail.com

\begin{abstract}
Motivation to study is the change of energy in an individual that can be signed with the emergence of feelings and reaction to reach goals. While self-discipline is a circumstance which form through a process that shows the values of self-confession, obedience, regularity, and orderliness to the applicable regulation, and to support good learning outcome should have motivation to study and also a good self-discipline.

This study aim to find out the relation between motivation to study and self-discipline with the learning outcome in electrical motor installation subject. The population of this study is the whole electrical installation expertise program's student in SMK Kapin. While the used sample is all the student who already got electrical motor installation subject as many as 60 students. The used method in this research is expost facto which used quantitative approach. The primary data is the motivation to study and self-discipline data, while the secondary data is the learning outcome data. The data analysis technique that used is hypothesis test and F-test that previously done prerequisite analysis test using normality test and linearity test.

The calculation result shows that the hypothesis test with 5\% of significant level obtained rcount $=0,6$ and rtable $=0,254$, because rcount $>$ rtable, then the Fcount $=16,03$ and Ftable $=3,15$ which mean Fcount $>$ Ftable so it can be concluded that there is a significant relation between the motivation to study and selfdiscipline with the learning outcome of electrical motor installation practice in electrical installation expertise SMK Kapin Jakarta.
\end{abstract}

Keywords: Motivation to Study, Self-Discipline, and Practice Learning Outcome

\begin{abstract}
Abstrak
Motivasi belajar adalah perubahan energi dalam diri seseorang yang ditandai dengan timbulnya perasaan dan reaksi untuk mencapai tujuan. Sedangkan disiplin diri adalah suatu kondisi yang terbentuk melalui proses yang menunjukan nilai-nilai pengakuan diri sendiri, ketaatan, kepatuhan, keteraturan, dan ketertiban kepada peraturan yang berlaku, dan untuk mendukung hasil belajar yang baik harus memiliki motivasi belajar dan disiplin diri yang baik juga.

Penelitian ini bertujuan untuk mengetahui hubungan antara motivasi belajar dan disiplin diri dengan hasil belajar praktikum siswa dalam mata pelajaran instalasi motor listrik. Populasi pada penelitian ini adalah seluruh siswa program keahlian teknik instalasi tenaga listrik SMK Kapin, sedangkan sampel yang digunakan adalah siswa yang sudah mendapatkan mata pelajaran instalasi motor listrik sebanyak 60 siswa. Metode yang digunakan dalam penelitian ini adalah expost facto menggunakan pendekatan kuantitatif. Data penelitian primer adalah data motivasi belajar dan disiplin diri, sedangkan data sekunder adalah data hasil belajar siswa. Teknik analisis data yang digunakan adalah uji hipotesis dan uji-F yang sebelumnya dilakukan uji prasyarat analisis menggunakan uji normalitas dan uji linieritas.

Hasil perhitungan menunjukan bahwa uji hipotesis dengan taraf signifikan 5\% di peroleh nilai rhitung $=0,6$ dan nilai rtabel $=0,254$, karena nilai rhitung $>$ rtabel, kemudian nilai Fhitung sebesar 16,03 dan nilai Ftabel $=3,15$ yang berarti Fhitung > Ftabel maka dapat disimpulkan bahwa terdapat hubungan yang signifikan antara motivasi belajar dan disiplin diri dengan hasil belajar praktikum instalasi motor listrik Program Keahlian Teknik Instalasi Tenaga Listrik SMK Kapin Jakarta .
\end{abstract}

Kata Kunci : Motivasi Belajar, Disiplin Diri, dan Hasil Belajar Praktikum

\section{PENDAHULUAN}

Pendidikan merupakan upaya untuk meningkatkan kualitas sumber daya manusia, oleh sebab itu pendidikan memerlukan penanganan yang sangat serius dari pemerintah. pendidikan memerlukan banyak perangkat diawali dari perangkat perundang-undangan yang memadai dan mendukung suatu sistem pendidikan sampai tingkat perangkat yang sangat penting dan menentukan yaitu kualitas pendidik di dalam berbagai lembaga pendidikan. Dalam lembaga pendidikan tersebut terjadi yang namanya kegiatan belajar mengajar. Beberapa faktor yang mempengaruhi hasil dari kegiatan belajar mengajar diantaranya adalah motivasi belajar dan disiplin diri.

Motivasi merupakan faktor dominan yang mendorong individu untuk melakukan kegiatan yang diinginkan, dalam proses belajar mengajar sehingga motivasi belajar merupakan potensi 
individu yang menjadi landasan utama terhadap proses pembinaan, pengembangan kepribadian dan kemampuannya, dimana hal tersebut menjadi sangat dominan dalam menentukan tingkat keberhasilan seseorang

Faktor lainnya selain motivasi belajar adalah disiplin diri. Disiplin dalam diri siswa dapat di lihat pada siswa tersebut terjun ke masyarakat (lingkungan sekolah). Di sekolah siswa benarbenar dididik untuk menjadi pribadi yang memiliki disiplin diri, di mulai dengan datang tepat waktu, memakai seragam yang sesuai, disiplin dengan mengerjakan tugas-tugas sekolah sesuai tepat waktu.

Jika siswa telah memliki motivasi belajar dan disiplin diri yang tinggi, maka hasil belajar siswa juga dapat menunjukan peningkatan, karena dengan adanya motivasi belajar siswa yang baik dan disiplin diri yang baik juga, maka siswa akan berpeluang besar untuk mendapatkan hasil belajar yang baik.

Berdasarkan latar belakang masalah di atas, maka peneliti tertarik untuk meneliti lebih lanjut hubungan antara Motivasi Belajar Siswa dan Disiplin Diri dengan Hasil Belajar Praktikum Instalasi Motor Listrik , Program keahlian Teknik Instalasi Tenaga Listrik, Studi Kasus SMK KAPIN Jakarta.

\section{METODE}

Tujuan dari penelitian ini adalah untuk mengetahui adanya hubungan antara motivasi belajar dan disiplin diri dengan hasil belajar praktikum instalasi motor listrik program keahlian teknik instalasi tenaga listrik studi kasus SMK Kapin Jakarta. Sampel penelitian ini adalah siswa yang sudah mengambil mata pelajara instalasi motor listrik sebanyak 60 orang. Penelitian dilaksanakan pada bulan September hingga Desember 2017- januari 2018 dengan menggunakan metode penelitian deskriptif korelatif yaitu survey untuk variabel motivasi belajar dan disiplin diri, sedangkan untuk hasil belajar praktikum menggunakan tes uji.

Setelah didapatkan data untuk penelitian selanjutnya dilakukan perhitungan prasyarat analisis yaitu dengan menghitung uji validitas dengan uji reliabilitas. Setelah melakukan uji prasyarat analisis selanjutnya dilakukan perhitungan normalitas variabel untuk mengetahui apakah data yang berdistribusi normal atau tidak. Selanjutnya dapat dilakukan perhitungan hipotesis dengan menggunakan rumus Pearson Product Moment, lalu menghitung signifikansi dengan menggunakan uji $\mathrm{F}$. Terakhir melakukan perhitungan linieritas dengan rumus regresi ganda untuk mengetahui hubungan antar variabel linier atau tidak..

\section{HASIL DAN PEMBAHASAN \\ Variabel Hasil Belajar Praktikum}

Tabel 1. Klasifikasi Hasil Belajar Praktikum

\begin{tabular}{|c|c|c|c|}
\hline Variabel & Indikator & Frekuensi & Presentase \\
\hline \multirow{2}{*}{$\begin{array}{c}\text { Hasil } \\
\text { belajar } \\
\text { siswa }\end{array}$} & $\begin{array}{c}\text { Di bawah } \\
\text { KKM }\end{array}$ & 1 & $1,67 \%$ \\
\hline & $\begin{array}{l}\text { Di Atas } \\
\text { KKM }\end{array}$ & 59 & $98,33 \%$ \\
\hline
\end{tabular}

Tabel di atas menunjukkan bahwa dalam kecenderungan hasil belajar terdapat sejumlah 59 orang yang mendapatkan hasil belajar dengan predikat di atas $\mathrm{kkm}$ yaitu $98,33 \%$ dari total sampel dan sebanyak 1 orang yang mendapatkan hasil belajar dengan predikat dengan di bawah $\mathrm{kkm}$ yaitu $1,67 \%$ dari total sampel.

Variabel Motivasi belajar

Tabel 2. Distribusi Frekuensi Data Motivasi Belajar

\begin{tabular}{ccccc}
\hline No & $\begin{array}{c}\text { Kelas } \\
\text { Interval }\end{array}$ & $\mathbf{F}$ & $\begin{array}{c}\text { F relatif } \\
(\%)\end{array}$ & $\begin{array}{c}\text { Nilai Tengah } \\
(\mathbf{X i})\end{array}$ \\
\hline $\mathbf{1}$ & $80-82$ & 6 & 10 & 81 \\
$\mathbf{2}$ & $83-85$ & 7 & 11,67 & 84 \\
$\mathbf{3}$ & $86-88$ & 8 & 13,33 & 87 \\
$\mathbf{4}$ & $89-91$ & 9 & 15 & 90 \\
$\mathbf{5}$ & $92-94$ & 15 & 25 & 93 \\
$\mathbf{6}$ & $95-97$ & 10 & 16.67 & 96 \\
$\mathbf{7}$ & $98-100$ & 5 & 8,33 & 99 \\
& Jumlah & 60 & 100 & 630 \\
\hline
\end{tabular}

Berdasarkan tabel di atas dapat terlihat bahwa frekuensi tertinggi berada pada kelas ke-enam yaitu pada rentang nilai antara 95 sampai 97 yaitu sebanyak 10 orang mahasiswa atau $16,7 \%$ dari total sampel

Tabel 3. Persentase Keterpenuhan Variabel Motivasi Belajar

\begin{tabular}{|c|c|c|c|}
\hline Variabel & Indikator & $\begin{array}{l}\text { Jml } \\
\text { Soal }\end{array}$ & $\begin{array}{c}\% \\
\text { keterpenuha } \\
\text { n variabel }\end{array}$ \\
\hline \multirow{5}{*}{$\begin{array}{l}\text { Motivasi } \\
\text { Belajar }\end{array}$} & Tekun menjalankan tugas & 6 & \multirow[t]{5}{*}{76,71} \\
\hline & $\begin{array}{l}\text { Lebih senang bekerja } \\
\text { mandiri }\end{array}$ & 4 & \\
\hline & Tidak cepat bosan & 4 & \\
\hline & $\begin{array}{l}\text { Tidak cepat menyerah } \\
\text { terhadap hal yang di } \\
\text { yakini }\end{array}$ & 6 & \\
\hline & $\begin{array}{l}\text { Senang mencari dan } \\
\text { memecahkan soal }\end{array}$ & 4 & \\
\hline
\end{tabular}


Berdasarkan perhitungan seperti nampak pada tabel di di bawah dapat disimpulkan bahwa persentase keterpenuhan variabel motivasi belajar yaitu sebesar $76,71 \%$.

\section{Variabel Disiplin Diri}

Tabel 4. Distribusi Frekuensi Data Variabel Disiplin Diri

\begin{tabular}{ccccc}
\hline No & $\begin{array}{c}\text { Kelas } \\
\text { Interval }\end{array}$ & $\mathrm{f}$ & $\begin{array}{c}\text { F Relatif } \\
(\%)\end{array}$ & $\begin{array}{c}\text { Nilai } \\
\text { Tengah }(\mathrm{Xi})\end{array}$ \\
\hline $\mathbf{1}$ & $70-72$ & 3 & 5 & 71 \\
$\mathbf{2}$ & $73-75$ & 7 & 11,67 & 74 \\
$\mathbf{3}$ & $76-78$ & 11 & 18,33 & 77 \\
$\mathbf{4}$ & $79-81$ & 15 & 25 & 80 \\
$\mathbf{5}$ & $82-84$ & 16 & 26,67 & 83 \\
$\mathbf{6}$ & $85-87$ & 7 & 11,67 & 86 \\
$\mathbf{7}$ & $88-90$ & 1 & 1,67 & 89 \\
& Jumlah & 60 & 100 & 560
\end{tabular}

Berdasarkan tabel di atas dapat terlihat bahwa frekuensi tertinggi berada pada kelas ke-lima yaitu pada rentang nilai antara 82 sampai 84 yaitu sebanyak 16 orang mahasiswa atau $26,67 \%$ dari total sampel.

Tabel 5. Persentase Keterpenuhan Variabel Disiplin Diri

\begin{tabular}{clcc}
\hline Variabel & \multicolumn{1}{c}{ Indikator } & $\begin{array}{c}\text { Jml } \\
\text { Soal }\end{array}$ & $\begin{array}{c}\% \\
\text { keterpenuhan } \\
\text { variabel }\end{array}$ \\
\hline $\begin{array}{c}\text { Disiplin } \\
\text { Diri }\end{array}$ & $\begin{array}{l}\text { menaati peraturan } \\
\text { sekolah }\end{array}$ & 4 & 70,28 \\
& $\begin{array}{l}\text { menaati peraturan } \\
\text { saat praktikum } \\
\text { mengerjakan tugas }\end{array}$ & 4 & \\
& $\begin{array}{l}\text { memiliki kesadaran } \\
\text { diri } \\
\text { membentuk perilaku } \\
\text { sesuai nilai yang } \\
\text { ditentukan }\end{array}$ & 2 \\
$\begin{array}{l}\text { Menerapkan norma- } \\
\text { norma dan nilai } \\
\text { kehidupan }\end{array}$ & 3 \\
\hline
\end{tabular}

Berdasarkan perhitungan seperti nampak pada tabel di atas dapat disimpulkan bahwa persentase keterpenuhan variabel disiplin diri yaitu sebesar $70,287 \%$.

\section{Pengujian Prasyarat Analisis Data}

Jika $\chi^{2}$ hitung $\leq \chi^{2}$ tabel berarti data berdistribusi normal, dan jika $\chi^{2}$ hitung $\geq \chi^{2}$ tabel berarti data berdistribusi tidak normal.

Tabel 6. Nilai Chi Kuadrat

\begin{tabular}{lccc}
\hline & $\begin{array}{c}\text { Motivasi } \\
\text { Belajar }\end{array}$ & $\begin{array}{c}\text { Disiplin } \\
\text { Diri }\end{array}$ & $\begin{array}{c}\text { Hasil } \\
\text { Belajar }\end{array}$ \\
\hline $\mathbf{d k}=\mathbf{k}-\mathbf{1}$ & 6 & 6 & 6 \\
Nilai $\boldsymbol{\chi}_{\text {tabel }}^{2}$ & 12,6 & 12,6 & 12,6 \\
Nilai $\boldsymbol{\chi}^{\mathbf{2}}$ hitung & 7,35 & 3,62 & 3,53 \\
\hline
\end{tabular}

Pada tabel normalitas pada penelitian ini dihitung dengan taraf signifikansi $\alpha=0,05$ dengan hasil yaitu pada variabel motivasi belajar dengan nilai $\mathrm{dk}=6$ diraih nilai $\chi^{2}$ hitung $=7,35$ sedangkan $\chi_{\text {tabel }}^{2}=12,6$, karena $\chi^{2}$ hitung $\leq \chi_{\text {tabel maka dapat }}^{2}$ dinyatakan bahwa variabel motivasi belajar berdistribusi dengan normal.

Dilanjutkan dengan variabel yang kedua yaitu Disiplin Diri dihitung dengan taraf signifikansi $\alpha$ $=0,05$ kemudian memiliki nilai $\mathrm{dk}=6$ diraih nilai $\chi^{2}$ hitung $=3,62$ sedangkan $\chi_{\text {tabel }}^{2}=12,6$, karena $\chi^{2}$ hitung $\leq \chi^{2}$ tabel maka dapat dinyatakan bahwa variabel disiplin diri juga berdistribusi dengan normal.

Variabel ketiga yang dijelaskan dalam tabel nilai chi kuadrat untuk menghitung normal atau tidaknya suatu sebaran dihasilkan nilai $\chi^{2}$ hitung $=$ 3,53 sedangkan $\chi^{2}$ tabel $=12,6$ dengan taraf signifikansi $\alpha=0,05 \mathrm{dan} \mathrm{dk}=6$. Maka dapat disimpulkan bahwa variabel hasil belajar siswa berdistribusi dengan normal karena $\chi^{2}$ hitung $\leq \chi^{2}$ tabel .

\section{Uji Hipotesis}

$\mathrm{H}_{0}=\mathrm{r}_{\text {hitung }} \leq \mathrm{r}_{\text {tabel }}=$ tidak terdapat hubungan $\mathrm{H}_{\mathrm{a}}=\mathrm{r}_{\text {hitung }}>\mathrm{r}_{\text {tabel }}=$ terdapat hubungan

Diketahui nilai $r_{\text {hitung }}=0,535$ dengan derajat kebebasan sebesar 59 dan taraf signifikansi $\alpha=$ $5 \%$ dengan $r_{\text {tabel }}=0,254$. Dilihat dari kriteria pengujian yang digunakan, terlihat hasil pengujian hipotesis tersebut menunjukkan $r_{\text {hitung }}>$ $\mathrm{r}_{\text {tabel }}$ maka $\mathrm{H}_{0}$ ditolak dan $\mathrm{H}_{\mathrm{a}}$ diterima yang berarti terdapat hubungan antara motivasi belajar dan disiplin diri secara bersama-sama dengan hasil belajar praktikum instalasi motor listrik. Pada perhitungan Product Moment di atas juga dapat disimpulkan bahwa terdapat hubungan yang positif antara motivasi belajar dan disiplin diri secara bersama-sama dengan hasil belajar praktikum instalasi motor listrik karena $\rho>0(\rho$ $\left.=\mathrm{r}_{\text {hitung }}=0,535\right)$.

\section{Uji Signifikansi dan Linieritas}

$\mathrm{H}_{0}=\mathrm{F}_{\text {hitung }} \leq \mathrm{F}_{\text {tabel }}=$ tidak terdapat hubungan yang signifikan

$\mathrm{H}_{\mathrm{a}}=\mathrm{F}_{\text {hitung }}>\mathrm{F}_{\text {tabel }}=$ terdapat hubungan yang signifikan

$\mathrm{F}_{\mathrm{yx} 1 \times 2}=11,48$ yang berarti $\mathrm{F}_{\text {hitung }}>\mathrm{F}_{\text {tabel }}$ terdapat hubungan yang signifikan antara motivasi belajar dan disiplin diri secara bersama-sama dengan hasil belajar praktikum instalasi motor listrik. 
Selanjutnya dilakukan perhitungan analisis regresi ganda. Berdasarkan perhitungan analisis regresi ganda telah didapatkan nilai $\mathrm{a}=42,57$, kemudian nilai $b_{1}=0,31$, dan nilai $b_{2}=-0,17$. Jadi persamaan regresinya: $\hat{\mathrm{Y}}=42,57+0,31 \mathrm{X}_{1}+0,17 \mathrm{X}_{2}$

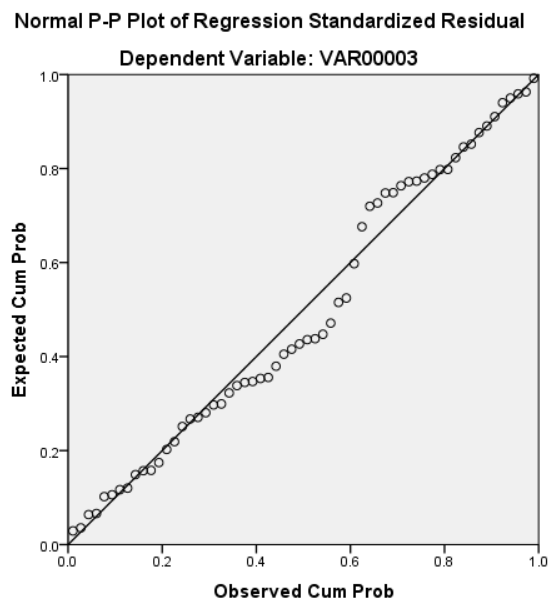

Gambar 1. Persebaran Variabel Motivasi Belajar dan Disiplin Diri dengan Hasil Belajar Praktikum Instalasi Motor Listrik.

\section{KESIMPULAN DAN SARAN \\ Kesimpulan}

Kesimpulan dari penelitian ini adalah terdapat hubungan yang positif dan signifikan antara motivasi belajar dan disiplin diri secara bersama-sama dengan hasil belajar praktikum. Hal ini ditunjukkan dengan uji korelasi yang menunjukkan $r_{y x_{1} x_{2}}$ sebesar 0,535 lebih besar daripada nilai $r_{\text {tabel }}=0,254$ dan $\rho>0$ maka bernilai positif dan $F_{\text {hitung }}=11,48$ lebih besar daripada $F_{\text {tabel }}=3,15$. Peneliti menyarankan siswa untuk terus meningkatkan motivasi belajar dan disiplin diri untuk mendapatkan hasil belajar yang baik.

\section{Saran}

1. Untuk subyek penelitian yaitu siswa program keahlian Teknik Instaslasi Tenaga Listrik SMK Kapin. Peneliti menyarankan untuk tetap meningkatkan motivasi belajarnya, dengan motivasi belajar yang baik maka akan membangun sikap yang baik pula, salah satunya adalah disiplin diri. Dengan dua hal tersebut akan membuat siswa mendapatkah hasil belajar yang baik.

2. Untuk orang tua berikanlah motivasi belajar dan terapkanlah disiplin diri pada anak untuk mendukung siswa agar mendapatkan hasil belajar yang baik di sekolah.

3. Untuk Kepala SMK Kapin dan Kepala Jurusan Teknik Instalasi Tenaga Listrik SMK Kapin, agar terus memberikan bimbingan terhadap siswa untuk menumbuhkan motivasi belajar dan disiplin diri siswa, karena tidak hanya akademik yang harus di tingkatkan, sifat dan perilaku siswa pun harus tetap ditingkatkan dan di jaga.

4. Untuk peneliti selanjutnya, sebagai bahan masukan dan pengetahuan untuk selanjutnya diteliti lagi variabel lain yang mempengaruhi hasil belajar siswa. Peneliti lain dapat pula melakukan penelitian komparatif atau perbandungan hasil belajar siswa yang mempunyai motivasi tinggi dan motivasi rendah.

\section{DAFTAR PUSTAKA}

Kunandar (2013). Penilaian Autentik. Jakarta. Rajawali pres.

Susanto, Ahmad (2013). Teori Belajar dan Pembelajaran Di Sekolah Dasar.

Jakarta. PRENADAMEDIA GROUP.

Purwanto. (2011). Evaluasi Hasil Belajar. Yogyakarta. Pustaka

A.M Sardiman (2011). Interaksi dan Motivasi Belajar dan Mengajar. Jakarta. Rajawali Pers.

Hamalik, Oemar (2009). Kurikulum dan Pembelajaran. Jakarta. Bumi Aksara

Uno, Hamzah (2008). Teori Motivasi \& Pengukurannya. Jakarta. Bumi Aksara.

Mahmudi, Ihwan (2009). Pengaruh Berpikir Kreatif, Disiplin Diri, Dan Kemandirian Belajar Terhadap Hasil Belajar Bahasa Arab Siswa Kmi Pondok Modern Darussalam Gontor Ponorogo. Jakarta. Universitas Negeri Jakarta 